\title{
Understanding the Experiences of Instructors as They Adopt a Course Management System
}

Charles R. Graham

charles.graham@byu.edu

Gregory L. Waddoups

Richard E. West

rw@byu.edu

Follow this and additional works at: https://scholarsarchive.byu.edu/facpub

Part of the Educational Psychology Commons

\section{Original Publication Citation}

West, R. E., Waddoups, G., \& Graham, C. R. (27). Understanding the experiences of instructors as they adopt a course management system. Educational Technology Research and Development, 55(1). 1-26.

\section{BYU ScholarsArchive Citation}

Graham, Charles R.; Waddoups, Gregory L.; and West, Richard E., "Understanding the Experiences of Instructors as They Adopt a Course Management System" (2007). Faculty Publications. 935.

https://scholarsarchive.byu.edu/facpub/935 
Running head: Instructors' CMS experiences

\title{
UNDERSTANDING THE EXPERIENCES OF INSTRUCTORS
}

\section{AS THEY ADOPT A COURSE MANAGEMENT SYSTEM}

\author{
Richard E. West \\ University of Georgia \\ Greg Waddoups, and Charles R. Graham \\ Brigham Young University
}

Richard E. West

Learning \& Performance Lab

The University of Georgia

(706) 621-7825

rickwest@uga.edu
Greg Waddoups Center for Instructional Design Brigham Young University (801) 422-4734

greg_waddoups@byu.edu
Charles R. Graham

Instructional Psychology \& Technology Brigham Young University (801) 422-4110 charles_graham@byu.edu 


\begin{abstract}
In this study, we used qualitative methods to help us better understand the experiences of instructors as they are persuaded to adopt a course management system and integrate it into their teaching. We discuss several patterns explaining how instructors implemented Blackboard, a CMS, by experimenting with individual features, facing both technical and integration challenges, and attempting to adapt Blackboard features to match their goals and practices. We also give explanations for why instructors either a) embraced the tool and grew more dependent on it, b) reduced their use of the tool to only some features, or c) discontinued the tool and actively sought replacement options. In this paper we explain why instructors fell into any one of these three areas and what implications this may have for training and support needs.
\end{abstract}




\section{UNDERSTANDING THE EXPERIENCES OF INSTRUCTORS}

\section{AS THEY ADOPT A COURSE MANAGEMENT SYSTEM}

While educational technology researchers have been studying the effects of using many different kinds of tools, from blogs and wikis to simulations and interactive whiteboards, there is one tool that has taken a quick and determined hold on higher education. This tool is the course management system (CMS), an adaptation of the learning management systems employed in corporate settings. Course management systems are now probably the most used educational technologies in higher education, behind only the Internet and common office software. Thomas Pollack (2003) reported that over 95 percent of colleges and universities now use some form of e-learning system. In fact, it is surprising just how quickly the CMS strategy has taken hold of higher institutions, which are usually known for their grip on traditional forms of teaching and for their reluctance towards change.

There are many kinds of course management tools, and they all function a little differently, but two main companies have dominated the CMS market: Blackboard and WebCT. Each is now being used by over 2,000 different academic institutions (Arnone, 2002; Pollack, 2003), and recently these two companies have merged and now collectively control the vast majority of the CMS market. As these tools have increased in popularity, there has also been some research, with mixed findings, into the potential impacts using these tools may have on learning outcomes (Hutchins, 2001; Klecker, 2002; Massimo, 2003; Morgan, 2003; Pollack, 2003; Vessell, 2001; Yip, 2004). However, there is little research directly studying the adoption and diffusion of CMS technologies in higher educational contexts.

We found one study that attempted to look at faculty perceptions as they participated in a 
CMS training program. The researchers administered a pre and post version of a survey to 20 instructors, measuring their perceptions of their own abilities in using the tool, the impact the technology could have on student learning, and the usefulness of the tool. Attitudes in all of these areas improved, seeming to indicate that the training would improve the likelihood of instructor adoption of Blackboard (Bennett \& Bennett, 2003). The training program consisted of a half-day presentation, two full-day workshops, and three shorter follow-up sessions that focused on hands-on learning of the technologies and showcasing of pedagogical approaches to integrating the tool into courses. The Bennett \& Bennett (2003) study is helpful in illuminating the changing perceptions of faculty members, but it reports data from too small of a sample, and in too narrow of a context (instructors receiving training) to provide generalizable knowledge about what it is like for an instructor to adopt a CMS.

While there has been little research looking at the adoption and implementation of CMS tools specifically, there is a wider body of literature discussing the adoption and diffusion of innovations in general. The variety of adoption models and theories is impressively large, and most of these can be categorized into three groups, with each group focusing most specifically on: a) organizations and systems, b) conditions and environments, and c) individual users.

Organizational or systemic adoption of innovations is an important lens for policymakers, leaders, and change agents interested in effecting change on a larger scale. Systemic adoption of new technologies and ideas can also create more permanent change, because, "a fundamental change in one aspect of a system requires fundamental changes in other aspects in order for it to be successful. In education, it must pervade all levels of the system” (Reigeluth, 1994). In the literature, the topic of systemic change in education began to be discussed seriously in the 1990s, no doubt largely influenced by Reigeluth and Garfinkle's Systemic Change in Education (1994). 
This topic continues to be studied and researched, but usually in a K-12 context (Dexter, 2005; Fleming \& Love, 2003; Joseph \& Reigeluth, 2005; Miller, George, \& Fogt, 2005). In higher education, there is less research concerning adoption and diffusion of innovations. However, Blackboard Inc., has a model used internally for understanding the institutional adoption of its web-based technologies, explaining that an institution moves through five stages of adoption (exploratory, supported, strategic, mission critical, and transformational) towards a fully integrated online instructional component. Like other models, the Gilfus Model, as it is called, is descriptive of stages an institution might pass through, but it offers little insight into how to use these descriptions to prescribe effective support strategies that may help instructors (Ellis, 2004; Yaskin \& Everhart, 2002; Yaskin \& Gilfus, 2001; Yaskin \& Gilfus, 2002).

Donald Ely is well known for a lifetime of research into educational technologies, and one area of research for which he is often referenced is his description of the conditions that must be present for the successful adoption of innovative technologies. Ely spent six months in 1989 investigating the adoption, implementation, and institutionalization of educational technologies in Indonesia, Chile, and Peru. He found that there were eight main conditions that aided the successful adoption of technological innovations: dissatisfaction with the status quo, existence of knowledge and skills, availability of resources, availability of time, existence of rewards or incentives, participation, commitment, and leadership (Ely, 1990). He later reiterated the importance of these eight conditions with evidence from subsequent research projects (Ely, 1999). Other researchers have continued to build on the foundation created by Ely, studying the perceptions faculty have towards the eight conditions (Surry \& Ensminger, 2002), as well as calling for instructional designers to do "adoption analysis" of the conditions surrounding the potential adoption of an innovation (Farquhar \& Surry, 1994). 
Perhaps the bulk of the research into the adoption and implementation of innovations has focused on the individual adopters. In this area of study, there are many researchers who have created models and guidelines for guiding change agents in helping people to successfully adopt and implement an idea or technology (Ellsworth, 2000; Havelock, 1995; Zaltman, 1977). A popular model in the 1980s was presented by Gene Hall and Shirley Hord. The Concerns-based Adoption Model (CBAM) was a description of the kinds of concerns, or foci, that adopters feel as they move through various stages of adoption. In summary, Hall and Hord believed that adopters progress through seven levels of concern: awareness, informational, personal, management, consequences, collaboration, and refocusing. At each stage, different support structures are needed to address these concerns. For example, encouraging a teacher to focus too much on adapting a technology to improve outcomes (consequences) may in fact be detrimental if the teacher is only becoming aware of the technology or is still struggling through learning the basics of the tool. The CBAM model is often cited in adoption studies, and the model has been revised by other researchers, including Christopher Moersch, who modified the CBAM model to create the Levels of Technology Integration (LoTi) model (1995; 1996)

Perhaps the most influential researcher in the study of the diffusion/adoption of new innovations (such as technologies, or ideas) is Everett Rogers. In his book, Diffusion of Innovations (2003), Rogers provides a model for understanding the adoption decision process from the point of view of an individual. In his model, Rogers asserts that adopters pass through five stages:

1. Knowledge — The individual learns about the innovation

2. Persuasion - The individual decides mentally what his/her position is in regards to the innovation 
3. Decision - The individual decides to adopt the innovation

4. Implementation - The individual actually adopts the innovation

5. Confirmation - The individual seeks reinforcement for the decision to adopt, or decides to discontinue using the innovation

In our study, we chose to use Rogers' ideas about the five stages of adoption to guide our interpretations. We did so because our early data analysis indicated patterns among our faculty members very similar to the five stages Rogers describes. In this way, it was a useful model for conceptualizing the experiences of the instructors at our university, Brigham Young University (BYU). However, because Rogers' research focus is on adoption, his model focuses on the intrapersonal and extrapersonal factors that lead a person to adopt or refuse to adopt an innovation. Four of the five stages of Rogers' model deal with issues leading up to adoption. What is lacking from Rogers' model is more understanding of how people implement an innovation that they have chosen to adopt, and what happens after they begin to implement the innovation. For example, the following types of questions remain: What happens during the implementation stage and before and after the confirmation stage? How can organizations help an innovation be implemented effectively? What kinds of struggles will people have as they implement the innovation? This paper is an attempt to address some of these questions.

Implementation is very different from adoption, according to most researchers, including Rogers (2003). Adoption processes are largely concerned with what leads a person to decide to use an innovation. Implementation, however, is the actual integrating of the innovation into a person's life until the innovation is finally institutionalized or a routine part of the person's experience. Hall and Hord (1987) point out that as an innovation becomes routine for a teacher, there are new challenges and different concerns, moving away from task-related concerns, such 
as technical issues of how to make the innovation work, towards impact-related concerns, which emphasize how to use the innovation to improve teaching and learning.

Because universities are investing large amounts of resources into purchasing and supporting CMS technologies, we need to better understand the kinds of experiences instructors have as they adopt and implement these technologies into their teaching. The context for this study was a campus-wide investigation of the adoption and implementation patterns of faculty instructors at Brigham Young University, a large private university in Utah that has been using Blackboard in some capacity since 1999. At BYU, the use of Blackboard has penetrated most colleges on campus, and the university has attempted to integrate other services, such as assessment services and the library, into the CMS. Our main research question for this project was: What have been the challenges, successes, and decisions affecting instructors as they have adopted features of the course management system and have worked to integrate this technology into their teaching?

Methods

\section{Data Collection}

Data were collected through semi-structured interviews with instructors $(n=\underline{31})$ and openended answers to a survey administered to instructors over two semesters $(n=124)$._The interviews and surveys were designed to provide feedback representing the diversity of CMS users on campus. In sampling for our survey participants, the survey was administered randomly to the population of CMS users on campus. In our final survey sample, all 13 colleges were represented in the surveys by professors $(n=74)$, adjunct/part-time instructors $(n=27)$, and graduate instructors ( $n=19$; see Figures 1 and 2$)$. The questions on the survey asked the participants how their use of a CMS has changed how they conduct their courses and use their 
time, as well as what challenges and positive effects they have had from implementing the technology (see Table 1).

Insert Figures 1 and 2; and Table 1 about here

In sampling participants for the interviews, we originally selected instructors randomly from every college on campus, and requested participation by email. When a particular college had a poor response rate, we continued to randomly select other faculty members from that college to petition for participation. Because much of our sample represented CMS users who employed the technology in very similar ways, we began to broaden our sample through theoretical sampling (Glaser \& Strauss, 1967) in order to find CMS users who integrated the technology differently. We did this so that we could verify how our developing theories and ideas matched the experiences of different kinds of users. For our theoretical sampling, we asked participants in our interviews if they knew of somebody in their college who used Blackboard in different, creative, or effective ways, or in some cases, a colleague who did not use Blackboard at all so that we could understand the perspectives of many different kinds of faculty members. We also used theoretical sampling to help fill holes that existed from a lack of sample in any demographical area. For example, when we found we had not interviewed very many female instructors, we purposefully focused on obtaining more female representation. In our final sample, 11 colleges were represented, including 26 males and 5 females (see Table 2).

Insert Table 2 about here 
The interviews were semi-structured in nature, allowing the participant and interviewer freedom to explore issues raised in one case that may not have been present in another. At first the interviews elicited more descriptive, or substantive (Glaser, 1978) information, such as which features of Blackboard were used, what motivated instructors to adopt new features, and what instructors considered the impact to be of using Blackboard in their teaching. As the research progressed, and patterns began to develop, less time was spent asking what features faculty members used, didn't use, etc., and more time was spent exploring with the instructors the reasons why they use the features they do, and what the impacts on their experiences have been. A description of the interview protocol is provided in Table 3.

Insert Table 3 about here

\section{Data Analysis}

Analysis began during the data collection phase of the evaluation. As we collected data we wrote down ideas for possible themes in an evaluation journal and in memos attached to interview transcripts. As we did this, categories in the data grew more evident. Later, we used the qualitative research tool HyperResearch (http://www.researchware.com/) to help manage the data. We began by setting up the major categories we were interested in as researchers (usage, knowledge, satisfaction, stability, efficiency and learning). We then used a constant-comparison approach within these categories to determine the sub-categories, properties, and relationships existing in these categories. The constant comparison approach (Glaser \& Strauss, 1967) is an analytical method where the researcher/evaluator first compares a portion of the data with another portion, determines whether they are alike or different, and then creates categories to 
represent these differences. New data are then compared against existing categories until a complex coding structure emerges. This process of constant comparison yielded many codes, which were used to code all of the interview transcripts. Once all of the transcripts were coded, each domain was re-analyzed to synthesize and determine the relationships between the codes and to identify the key findings relevant to each particular domain.

Establishing trustworthiness of qualitative data. Merriam (1998) explains that there are two important elements to judging the value of a qualitative project: the internal and external validity of the project. Merriam defines internal validity in qualitative data as pertaining to how closely the findings match reality. Methods commonly used to establish internal validity include triangulation, peer debriefing, member checking, and negative case analysis. For this project, the research team triangulated the findings between surveys and interviews from multiple academic departments. We used peer debriefing techniques and member checking to validate the descriptions of the data and the interpretations. Finally, once we started developing theories about the data, we used negative case analysis, a method that emphasizes looking for ways to disprove emerging theory. Through this negative case analysis we rejected some theories and adapted others so they better represented all of the data.

Merriam (1998) explains that external validity is "concerned with the extent to which the findings of one study can be applied to other situations" (p. 207). Merriam believes external validity can be increased through rich, thick description that includes descriptions of how typical cases in a case study are of the general population. Merriam also emphasizes the importance of multi-site designs, or research designs that require collecting data at multiple sites and in different situations. In this project, we have attempted to provide as much thick description as possible, and the project was designed to study many multiple contexts, in that cases were taken 
from as many departments as possible, and represented faculty differences in gender, teaching experience, technology proficiency, and other factors. A research journal was also diligently kept to describe our thoughts and the steps we took to complete this project.

Findings and Discussion

Our analysis revealed several patterns that helped us understand aspects of the experiences of instructors at Brigham Young University who begin to adopt and implement Blackboard. To describe our findings, we will first present a case study that shows our ideas in the context of one instructor's story. We will then discuss the patterns we found and how they deepen the understanding provided by Rogers' (2003) Innovation-Decision Model.

\section{Case study: A typical instructor's experience}

Mr. Maddux teaches in the College of Biology and Agriculture at Brigham Young University. His teaching responsibilities include both large undergraduate classes of 100-150 students, and smaller graduate courses of 8-12 students. He uses Blackboard in both situations, but in different ways. His first introduction to Blackboard came about three years ago, when he became acquainted with some Blackboard features through talking with colleagues in his department and observing how they were using Blackboard. After creating his first Blackboard course, Mr. Maddux did not experiment with very many of the features at first, but used Blackboard only for email. At this same time, Mr. Maddux was learning how to use PowerPoint, and it was easy to post his PowerPoint lectures on his Blackboard course for his students to download. His students liked this, and their feedback encouraged him to use Blackboard more. "I think it's useful for getting information to students," he said. "And I think they've appreciated having access to that. I think it's allowed a little more freedom in the classroom for students to ask questions and not feel they're going to miss something while they're writing it down." 
For the most part, Mr. Maddux has enjoyed using PowerPoint and Blackboard to deliver his instructional materials, and like most instructors, he seemed to feel that the two tools compliment each other. He is worried, though, about the tendency to give more to students because it is so easy to do in digital form. As Mr. Maddux said, "The one thing that I've noticed . . . sometimes I get, I find myself wanting to give too much information. . . . It's almost like replicating the chapter in a visual way."

Slowly, over time, Mr. Maddux experimented with more and more of Blackboard's features. Three semesters ago he began using the gradebook feature. However, he only uses this feature to display grades to students, and for keeping track of the grades during the semester. At the end of the semester, he downloads the grades to Excel so he can do more complicated grade calculations that are not possible in Blackboard. In this way he has adapted how he uses Blackboard's gradebook feature so that it better helps him in the way he handles grades. He also began using group discussion boards for his smaller classes. He has never tried using discussion boards with his larger classes, and is scared to do so. He is not sure how to moderate such large discussions because he likes to read the things the different groups are posting and give his input on occasion. "I'm afraid, I think I'll be overwhelmed. The smaller class I have anywhere from 8 to 12 students. It's something I can go in everyday and check on," he said. "It's probably been more fear oriented, fear that it might take so much time."

This past semester, Mr. Maddux and his wife, who is also a part-time BYU instructor, experimented with a new feature: online tests. They chose to start doing tests online so that it would save class time, and allow them to do other activities during class. For Mrs. Maddux especially, who gives a weekly quiz, this was anticipated to be a great timesaving feature. However, they found that Blackboard was agonizingly slow to create tests because they could 
only create one test item at a time. Because their tests require a lot of pictures, it took "hours" to upload the images one by one into Blackboard. This was an experience they did not enjoy and hope to never do again. Instead, Mrs. Maddux will reuse the same quizzes every semester. Mr. Maddux found an easier way to adapt the testing feature by posting a PowerPoint full of images, and then having the test be only text-based with references to the PowerPoint for the images the students will need. However, this requires students to download the PowerPoint.

Overall, Mr. Maddux's feelings about Blackboard are mixed. "Some aspects I really appreciate, and other aspects I have grown to dislike intensely," he said. However, because Maddux and his wife have invested so much time in setting up their Blackboard courses, they hope the university never stops supporting Blackboard in order to acquire a new tool, unless there would be a way to set up their course in the new CMS without re-constructing all of the quizzes again. Now that they have their courses set up, they want to use these courses for many semesters to come. They have grown dependent on the tool to some degree because of the time and energy they have invested into setting up their courses. "If the decision was to pull the tool and to utilize another one, it would have to be one that could be easily learned by faculty members because if not there would be an outright rebellion. ... If the plug were pulled now, she (his wife) would be in a world of hurt. It'd be all of last semester's time and effort right down the drain. Even though she's not happy about the time it took, I know she'd not want to do it again."

\section{Aspects of Instructors' Experiences with a CMS}

As we interviewed instructors like Mr. Maddux and considered their experiences, we began to see many patterns emerge. These patterns explained aspects of the instructors' experiences and helped us to better understand the process of adopting and implementing Blackboard at BYU. While it seems that all of the instructors we observed and talked to 
experienced these patterns, they sometimes did so in unique ways or to varying degrees due to the effects of other variables, such as the instructor's previous experience with educational technologies, the presence or absence of the conditions necessary for change to occur (Ely, 1999), and pressure existing from departments, colleagues, and students about Blackboard. The patterns we have found explain that instructors rarely adopt all of the features of a multipurpose tool like Blackboard, but instead face many smaller adoption decisions as they weigh the advantages and disadvantages of using individual features of the tool. We will explain some of the events that instructors experience as they adopt Blackboard's features, explaining how this leads them to re-evaluate their use of the CMS features, and decide to either continue to use the tool or some of its features (confirmation), scale down their use of the tool to only some of its features (reduction), or discard the tool completely in favor of other options (discontinuation, see Figure 3). Following are some of the patterns that we identified in the experiences of instructors at BYU as they began to implement Blackboard:

\section{Insert Figure 3 about here}

1. Instructors begin using Blackboard by experimenting with one, or a few, of its features rather than adopting the entire tool.

2. Each time instructors attempt to adopt a feature of Blackboard, they experience challenges, both technical and challenges with integrating the tool into their teaching. As part of the technical challenges, instructors experience time and energy costs, and early efficiency payoffs are needed to compensate and to encourage instructors to continue using the CMS. Instructors turn to their colleagues for feedback and support during the 
challenges of learning how to overcome the technical aspects of a feature._Along with technical difficulties, instructors also struggle to make the feature fit into their regular practice and routine. As part of the integration challenges of implementing a feature of Blackboard, instructors often are forced to reconsider their practices, whether consciously or subconsciously; they face new challenges and often uncertainty about how to use the feature effectively; and they seek feedback from students and teaching assistants as confirmation points. Instructors who experience success in integrating the feature effectively into an aspect of their practice often then experience new excitement and enthusiasm for the tool or for their job.

3. Sometimes as instructors grow more familiar with a particular feature, they try to change the look of a feature or the methodology for using the feature so that it is different from the original intention and reflects the instructors' own individuality. This adaptation, or re-invention, of a particular feature reflects an effort to bend the tool to fit the instructors' needs and wants.

4. Eventually, after an instructor has attempted to implement one or several Blackboard features, they reach Rogers' Confirmation phase, where they now re-evaluate their use of the CMS or some of its features. We found three possible decisions that instructors make: a) continuation, where they decide that Blackboard is a useful tool for their needs and gradually grow more and more dependent upon the tool; b) reduction, where they decide to use Blackboard only minimally, and do not feel tied to the tool but open to other options; and c) discontinuation, where instructors reject Blackboard and seek other options or their online instructional needs. 
An important point to remember is that these patterns/events do not necessarily happen linearly. Some instructors approach the implementation of a feature of Blackboard by first considering the integration challenges. For others, the technical challenges are much easier to overcome, and they approach the integration and technical challenges simultaneously. Understanding these different processes associated with the implementation of Blackboard can provide insight into why some instructors seem to use Blackboard more effectively than others, and how universities can better support and train instructors to use educational technologies.

\section{Faculty Implementation Patterns}

Throughout our discussion of these findings, when we refer to numbers of instructors who indicated they had experienced a particular pattern, we are referring to instructors that we interviewed, not surveyed.

\section{Decision to Adopt}

Our analysis of the implementation experiences of instructors begins with their decision to adopt and to attempt to implement Blackboard into their teaching. We found that most instructors at Brigham Young University arrive at adopting Blackboard in the way described by Rogers (2003). They first learn about Blackboard, usually from either campus announcements (six mentioned this) or from their colleagues in their department (at least 17 instructors -50 percent), as in Mr. Maddux $\underline{\text { s }}$ case presented earlier. Sometimes the decision to adopt is not made by the instructor alone, but by others-for example, a department supervisor who decides a general education course will be accompanied by a Blackboard course. When instructors do make the decision alone, they usually choose to adopt Blackboard because they feel one or two features will provide an efficiency benefit. In other words, instructors want to do what they are already doing faster and easier, and this is often the initial reason why they choose to use the 


\section{tool. Instructors made comments such as, "What really motivated me to start using Blackboard} was first of all the gradebook, it was convenient," or "That's one of the big reasons why I use it [Blackboard]. Students can see their progression in the class, their grades." Thus, instructors usually were not adopting the whole tool, but only a particular feature or two of the tool at first.

In some cases, instructors become persuaded to try (or for the minority, to not try) the tool, because of pressure (real or perceived) from students, colleagues, or administration. At least 13 instructors interviewed mentioned this kind of pressure coming from students.

\section{Experimentation}

Instructors usually do not begin using all of Blackboard's features at once, but rather experiment with individual features that they feel directly address an instructional or organizational need, or goal, that they have. Rogers (2003) calls this the "trialability" of a particular tool. In Mr. Maddux's case, he began using Blackboard for simply emailing his students. He could have done the same thing using many other tools, but it was also a way for him to experiment with a feature of Blackboard.

Another example of experimentation was a professor, an avowed skeptic of new educational technologies, including Blackboard, who had never considered using the tool until he decided he needed a way to handle communicating grades to students in a very large (200 students), introductory course. In this way, he experimented with Blackboard by using only the gradebook feature. However, after setting up his course specifically to distribute grades, he decided to begin using other features as well, such as the course documents feature. Like this professor, most instructors seem to initiate their use of Blackboard by experimenting with only one or two features. After adopting these features, if their experience is positive overall, instructors often choose to experiment with other features, as Mr. Maddux did by experimenting 
with the gradebook and assessment features At least nine of our participants indicated that one

feature initiated their use of Blackboard, after which they experimented with other features.

When experimenting with the first feature or two that they are trying to adopt, the instructors may not even feel that they are in favor of Blackboard, or that they have made a decision to use or not use the tool. They are simply "trying it out" and exploring its functionality. At this stage, because instructors are experimenting and do not want to commit to receiving formal training, it can often become frustrating if the CMS is not intuitive. Several instructors (seven) explained that some of its features are difficult and confusing because they are not "intuitive" and do not function the way the instructors expected they should, or are not named in a way that clearly describes the purpose of the function. As one professor said, "If it's not really apparent, then you might not find some of the tools. There may be tools on Blackboard that can answer some of my problems that I don't know about." For example, professors have a hard time finding how to enable/access the virtual chatting features in the control panel, and we suppose this is one reason, among others, why this feature is so infrequently used.

\section{Technical Challenges}

As with all new technologies, ideas, or practices, it takes time and effort to learn how to use Blackboard. However, we found that there are two learning challenges for instructors as they begin to use a Blackboard feature: challenges with gaining technical competency with the tool as well as integration competency. The first of these is similar to what most research studies would describe as a learning curve, in other words, learning how to use the tool and which buttons to push and when to achieve the desired result. These challenges begin as instructors experiment with the feature and continue until they become comfortable and confident. 
As would be expected, the technical challenges are easier for instructors with previous experiences with technology. For these instructors, it may not seem like a challenge at all. However, for instructors with little experience with technology, learning the technical aspects of Blackboard can be very intimidating and may seriously hinder the kinds of choices the instructor makes about using the tool. For example, one instructor received funding to hire a teaching assistant to help him set up a Blackboard course and to teach him how to use a few basic features. During an interview, we asked this professor whether he might consider using other Blackboard features. He said he would, except that he was intimidated because he still did not have the technical competency required. "I'm not sure I can do it from here, I'm not that competent in it. It took a lot of time — a lot of time — to prepare the Blackboard," he said. "I really don't know how to do it that well."'Most instructors can overcome these technical challenges more easily than this instructor, but it requires a time and energy cost.

Many are surprised by how much time it takes to set up a Blackboard course the first time-especially if the instructor is trying to upload many years' worth of materials. At least 14 instructors mentioned the time/energy drain it took to initially learn how to use a Blackboard feature. One instructor in this situation said, "It [Blackboard] saves you time in the long run. It takes an enormous amount to set up. It takes me 20-30 hours to set up a Blackboard site at the beginning. It takes me a full week of work to set up the Blackboard site. Now, once it's set up, the semester goes a lot more smoothly for me, but it takes a huge initial outlay of time." Besides the time/energy cost of setting up a Blackboard course, there are also costs with learning to use each new feature adopted. When instructors do not consider exploring new educational technologies as part of their instructional mandate, then taking the time to overcome the technical challenges associated with learning to use a feature of Blackboard becomes a lower 
priority. "You also have to balance as a teacher how much time you spend on things ... how much time the technology is going to cost you. It does take time," one instructor said.

Efficiency payoffs. Because of the time and energy costs involved in overcoming the technical challenges of learning a feature of Blackboard, instructors need to feel early that they are, or soon will be, receiving enough of an efficiency payoff to make the commitment worthwhile. While added learning benefits are nice, at this point in the experience, instructors need efficiency benefits - they need Blackboard to automate their tasks and save them time to compensate for the initial time/energy lost.

For the most part, BYU instructors feel Blackboard provides these efficiency payoffs, and this motivates instructors to continue progressing towards a greater focus on effective integration practices. However, when a feature of Blackboard has stability problems, efficiency payoffs can be erased. If this happens too early in the adoption process for an instructor, it can dissuade the instructor from using new Blackboard features, or to discontinue using Blackboard features they have already adopted. This has become a major problem for BYU as stability problems have been increasing, and are increasing in the most critical areas. For example, we have had major problems with losing test scores, students being barred from entering a course or from taking a test, critical emails being lost, etc. These stability problems have negated the efficiency payoffs for most instructors to some degree (20 participants mentioned stability issues in our interviews) and discouraged many from using these features and from experimenting with other features of what is considered to be an "unstable" product.

Feedback from colleagues. While many instructors do attend university training sessions on Blackboard and indicated that these were helpful, it appears to be much more common for instructors to learn about how to use Blackboard from talking with other people in their 
department. One example is a younger professor who, upon being hired, was told by the other instructors in the department that "You better just use it and get used to it because it's going to be part of the normal procedure here on campus." This new instructor valued the opinion of his colleagues, so he said that he "just jumped into it and started using it." Another professor had a similar experience and said that "The [program] director ... sold me on the idea, he came and spent five minutes with me, and I thought, 'This is terrific,' and I've used it ever since."

It seems that feedback from colleagues is especially important for instructors when they are experiencing technical challenges. During this time, they want confirmation from colleagues that the effort will be worth it. We also found that sometimes the "colleague" that trains an

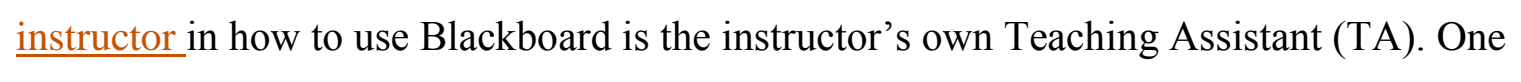
example is a younger professor asked to teach his department's large introductory course. He quickly realized he needed something to help him organize his instruction for so many students, and it was his TA's idea to use Blackboard, and it was his TA who first taught him about how to use the tool. Other professors rely so heavily on their colleagues and TAs that they will only use Blackboard if others set up their courses for them. For example, one professor remarked, "In the media classes, I have media savvy kids that will help me. So all I have to do is use it, I never have to set anything up. They set everything up for me. I just say, 'This is what I want,' and they set it up for me. I know that's awful, but it's true!" These instructors will also turn to colleagues and TAs after setting up a course when they have questions about how to use a feature of Blackboard, they will often ask do this before calling computer support personnel. This finding has prompted BYU to consider adding TA training to the regular instructor training about educational technologies, and we believe that TAs may be a critical change agent in the adoption/implementation process that are not taken as seriously as they should be. 


\section{Integration Challenges}

A second challenge that instructors experience is not a struggle to understand how to use Blackboard's features, but how to use these features effectively to achieve their goals - in other words, how to integrate the features successfully into their practice. Often this lack of integration knowledge is deepened because the instructors have not seen any of their colleagues using the features, so they struggle to understand how to apply them to teaching their particular subject matter. A few (out of many) examples of some integration knowledge gaps that we found were knowing how to:

1. Use online testing while still keeping the tests valid and cheating at a minimum.

2. Effectively use a virtual classroom or synchronous online chat feature.

3. Use Blackboard for courses that are hands-on and tactile, such as art.

4. Use discussion boards so that the discussion is useful and effective.

5. Moderate online discussions without spending an excessive amount of time.

One of the most common difficulties instructors have in learning how to integrate Blackboard into their teaching is understanding how to use the discussion/collaboration_features in a way that maximizes student learning without requiring an excessive amount of student or instructor time. About half of our participants seemed to indicate difficulty with integrating these tools into their teaching. Most instructors know how discussion boards and chatting work, but they do not understand how to teach online, moderate online discussions, integrate this type of discussion into a typical face-to-face course, adapt their teaching strategies and styles to accommodate online discussions, or make appropriate decisions about when an online discussion can be an effective method. One case was of a graduate instructor who teaches a large introductory course of over 100 students. The course is entirely online, but until now she has not 
used any of Blackboard's interaction/collaboration features. Instead, the course relies on a series of units that the students work through, and they then take tests to verify their understanding of the material. One of the main complaints that she receives from students is that they would like more interaction with other students and with herself. It seems that in this context, where there is no face-to-face interaction, that it would be valuable to use some of Blackboard's discussion tools. However, the instructor did not use these tools, partly for practical reasons such as her poor typing abilities. Part of the reason why she didn't use these tools, however, seemed to be that she was not trained in moderating online discussion and didn't know where to begin. She also didn't know the difference between asynchronous and synchronous communication features, and thought they were all the same.

Reconsidering practice. As instructors struggle with the challenges of how to effectively use Blackboard features in their courses, they often express apprehension towards online teaching because they are more familiar with face-to-face teaching. For example, one instructor said about using the discussion features that "for some types of classes. I just don't know how I'd use it. I don't know how other people use it. The type of class I teach is discussion-based in class." Another professor expressed a common worry about the same set of features that many do not know how to moderate online discussions without spending too much time on that aspect of the course: "I shy away from that right now because I'm thinking about how I would manage that, I'm thinking it's going to take more time to manage that discussion board and I'm not willing to invest the cost right now to do that. I simply don't know, there's the unknown: what is that going to do?"

As these cases show, for some instructors, learning to overcome integration challenges associated with using a new Blackboard feature may mean reconsidering their own sense of what 
is good pedagogy, or even what the best methods are for class management, and what their responsibilities should be as teachers. When instructors reconsider their practices it can often be something as simple as realizing that the instructor can now communicate with students more than in the past and considering whether s/he should do so. Going back to the example of Mr. Maddux, reconsidering practices for him could have been discovering that delivering electronic lectures allows students to take notes in new ways that should be explored, or that he should perhaps be more prompt with grades because the students will be looking for their scores online.

Setbacks/uncertainty \& student feedback. As instructors try to integrate Blackboard features into their practices, there are often setbacks where it appears that learning is negatively impacted. An example of this type of challenge is a professor who adopted several Blackboard features, but found that they encouraged some behavior from students that he did not feel was conducive to learning in his courses (for example, students stopped taking notes or were more likely to skip class because all material was available online). This professor struggled with how to use the features of Blackboard that he felt worked well for him, and how to justify to students his decision to not use the features he did not feel worked well. This setback proved more challenging than learning the technical aspects of the course documents feature of Blackboard, and it made him uncertain about how to effectively use Blackboard in his courses.

As instructors explore ways to integrate Blackboard features into their practices, there is also occasionally uncertainty about whether or not their methods for using the tool are good ones. This uncertainty can be increased through negative comments from students, who may have had bad experiences with Blackboard features in other courses and then discourage future teachers from using the same features for legitimate and effective purposes. As we discussed previously, we found that at least 13 participants mentioned the impact that pressure from 
students had on their decisions to use Blackboard's features. For example, one instructor explained that when he considered using virtual chatting features, the students were strongly against it. "Nobody was really smitten with that idea, so I abandoned it," he said, even though he still feels the tool would be helpful in the context of the class he teaches. It could be that as instructors turn their attention towards integration issues, the importance of student feedback for promoting or discouraging implementation of Blackboard may become more influential.

Successes/excitement. When instructors are able to overcome some of the integration challenges and setbacks, and if they think that they have found a successful way to integrate a feature of Blackboard into their instruction, they often feel a rewarding sense that they have succeeded a little more as an instructor. "I use Blackboard for all of my classes because it is a little gift from heaven," one instructor said, before explaining how she felt using several features of Blackboard was helping her be a better teacher. This feeling of success is sometimes accompanied by a renewed excitement for teaching. For example, one instructor who is not very technology savvy was excited that he was now successfully teaching a blended (online and faceto-face) course. "This is still rather exciting that I have been able to pull it off at all," he said. Some instructors, instead of feeling this success grow continually frustrated with Blackboard or with some of its features. To them, the integration challenges appear to be insurmountable and they grow more likely to look towards other tools to fulfill their needs.

\section{Adaptation (Re-invention)}

Adaptation, as we call this pattern, is referred to as re-invention by Rogers (2003). In his book, Rogers describes re-invention as "the degree to which an innovation is changed or modified by a user in the process of its adoption and implementation" (p. 181). We have chosen the term "adaptation" to emphasize the connotation that the instructors are adapting the tool to 
meet their own unique needs, and to connote that the changes might be small—-much smaller than might be expected with the term "re-invention."

Instructors adapt Blackboard when they use the tool's features in atypical or unexpected ways to achieve their goals. A common adapted feature is the discussion board, which is often used for many things besides actual discussions. Out of the instructors we interviewed, about one-third adapted the discussion board feature to do something other than moderate discussions. For example, because there is no space in Blackboard specifically for students to post materials for other class members to download, instructors often have students post their reports, articles they find, etc., on a discussion board. Some instructors use the discussion boards as a form of digital dropbox where students turn in homework. Others use it as a form of quiz, or assignment, where students simply respond to questions posed by an instructor, but where there is no real discussion with other members of the class.

Other examples of adaptation include the common practice of using the gradebook only to communicate grades before downloading the grades to Excel for actual calculation (about two-thirds of instructors indicated doing this); and less common practices of adding or taking away buttons on the main navigational menu; adding class or department logos to a course; and using Blackboard courses to organize research groups, instead of student groups. Mr. Maddux, frustrated with how long it took to upload images to Blackboard quizzes, made a simple adaptation by posting a PowerPoint full of images, and then having a quiz with no images that instead referred students to the PowerPoint for the images they would need. We feel this qualified as an adaptation because he was using the assessment features in ways they were not designed by having an accompanying PowerPoint of test images. 
The adaptations made by instructors are usually not large ones—at least not as large as might happen with other kinds of technologies. This is because most instructors perceived Blackboard to be a rigid tool that did not allow for very much customizability or adaptability. In fact, the most common request from instructors for improving the tool, indicated by about one half of the instructors interviewed, individual needs. For example, many instructors wished that there were more options in the gradebook for spreadsheet-like functions. "It's not my primary gradebook because I can't do anything with the scores. It's not a spreadsheet," one instructor said. Instructors also found the quiz feature inflexible because it did not adapt well to implementing multimedia, or to importing large amounts of questions or information. "It's too clumsy to work in anything more than a quiz," one professor said.

\section{Confirmation}

After experiencing these aspects of the adoption process, instructors reach a decision point where they either reject the Blackboard features they are using or continue using them and building their entire course structure around those features. This may be a deliberate, thought-out decision, or an unconscious one hardly noticed by the instructor. But at this point, the instructors re-evaluate the Blackboard features they are using and decide whether to continue using the $\underline{\text { features (continuation), to discontinue using some of the features (reduction), or in a few cases, }}$ $\underline{\text { to discontinue using Blackboard completely (discontinuation). }}$

Continuation. If the instructors decide that the Blackboard features they are using do meet their personal goals and objectives, then they strengthen their dependence on the tool through experimenting with and implementing more of Blackboard's features. "[When] I learn a thing about Blackboard, I tend to use it," said one instructor, a high user of the tool. Gradually 
the courses taught by these instructors change as Blackboard's features are more tightly woven into the instruction and organization of the courses, until the instructors cannot conceive teaching the course without Blackboard. These are the instructors most dramatically impacted by Blackboard stability problems because when Blackboard is not working, or if a particular feature that they use frequently is not working, then they feel that a major part of their course is absent. These are also the professors who are most vocal about the permanence of Blackboard at BYU. "If the decision was to pull the tool and to utilize another one, it would have to be one that could be easily learned by faculty members because if not there would be an outright rebellion," one instructor said.

Reduction. Because, as we found in this study, instructors see Blackboard as a collection of many features that can be individually adopted or rejected, it is common for instructors to decide to continue using some Blackboard features while exploring other options as well. For example, one instructor explained that there were three areas where he needs online support for his instruction, and he felt that Blackboard fulfilled his needs in one area $100 \%$ (central repository of documents), met his needs about $60 \%$ in another area (online discussion boards), and failed miserably in the third area (gradebook). This instructor chose to continue using the features of Blackboard that he liked, while discontinuing the other features in favor of alternative tools. A reduction decision has its own challenges, however. For example, as one instructor said, "If Blackboard has 10 features, and they are all stable, and four of them I like and six of them I don't, I've found you get pressure from people [students] to use the other six." Despite these challenges, we found that most instructors who make a reduction decision are happy to continue using Blackboard for some purposes, but they do not feel as tied to the tool and they are more open to the university investigating other options. 
Discontinuation. If one or several of Blackboard's features are not well matched with the instructors' objectives, then we found that the instructors may instead seek other options to better meet their needs, and so these instructors choose to discontinue using Blackboard completely. One example of this pattern was a professor who was technology-proficient, and experimented with several of Blackboard's features. After using Blackboard, he felt that "Blackboard seems to be created with people who know a lot about technology but very little about education. So they develop things that increase efficiency for the student but decreases effectiveness in education." Many instructors did not share this opinion, but this particular professor felt that many of Blackboard's features did not support, but rather undermined, his pedagogy. Because of this, he discontinued using the tool completely. "Blackboard solves a lot of problems I just don't have and creates some new ones," he concluded.

Other instructors who also reached this stage of adoption and decided to discontinue using Blackboard instead decided to seek other online alternatives, such as creating/maintaining their own personal websites, or using server space provided by their department. Other instructors increased their reliance on outside email services, blogs, wikis, instant messaging clients, or other online tools.

\section{Conclusions}

In this study, we sought to better understand the experiences of instructors as they adopted a course management system and integrated it into their practice. We found that many aspects of the instructors' experiences matched elements of Rogers (2003) adoption model. Specifically, we learned that instructors began the adoption process through learning about the CMS, often through their students or colleagues. While being persuaded by these peers, instructors usually adopt a CMS for only one or two of its features with the goal of doing what 
they already do more efficiently. They then experiment with the CMS, and at this stage of the process, intuitive usability is crucial because the instructors have not yet committed themselves enough to the tool to spend the time to "be trained." This finding may indicate why training so often does not lead to successful adoption/integration of a technology. There are many research studies conducted with the goal of improving faculty training (Ali, 2003; Bennett \& Bennett, 2003; Fitzgibbon \& Jones, 2004; Irani \& Telg, 2001; Kagima \& Hausafus, 2001; McCarney, 2004), but perhaps institutions should study how to provide more fertile opportunities for experimentation, as we found that this occurs before training and may indicate the likelihood of successful CMS adoption.

After experimenting with some aspects of the CMS, instructors usually faced technical and integration (pedagogy, or practice) challenges. As they grew more comfortable with the tool, some tried to adapt the tool to support different types of pedagogies. Based on how successfully the instructor overcame these implementation challenges, the instructor decided to continue to adopt more features of the CMS, reduce their use of the CMS to only the basic features, or discontinue use of the tool completely in search of other options.

As we learned in more detail about these aspects of the instructors' experiences with a CMS, we were better able to understand a few of the variables determining why some instructors are more successful with the tool than others. Many of these findings, it would seem, also have implications for the adoption of other educational technologies, especially those adopted on a wider, institutional basis. For example, it was important to learn the role that TAs, students, and colleagues could play in the successful implementation of a CMS, and the pressure some instructors feel to adopt the tool. In the case of the instructor mentioned in the previous section who chose to discontinue using Blackboard for pedagogical reasons, he found that if he was only 
interested in using some of Blackboard's features, he was pressured from students to use other

features he did not want to use.

If Blackboard has 10 features, and they are all stable, and four of them I like and six of them I don't, I've found you get pressure from people to use the other six. So if I'm in class and I say, here's a quote . . , a young woman raises her hand and says 'Can you put that on Blackboard?' Well, if I'm using Blackboard, it's awfully hard to say, 'Yeah, I can, but I don't believe it [is good instruction],' and they all think, 'Good grief'. Whereas if I don't use [Blackboard at all], I can just say, no, I don't use it."

Pressure from students led this professor to reject using the CMS completely, rather than reduce his use to only some features as was typically the case. While not as drastic, we found that for many instructors, pressure from students, colleagues, and TAs guided their decisions about using Blackboard, and that these decisions were not always based on pedagogical needs.

$\underline{\text { In this research we also learned the importance of early efficiency payoffs so that }}$ instructors remain motivated to continue implementing a feature from a CMS, as well as the detrimental nature of stability problems to overall adoption efforts. Other researchers have also found that early stability problems can negate technological benefits and impede adoption. In one study, researchers found almost universal complaints of critical breakdowns in an enterprisewide e-learning system (Dutton, Cheong, \& Park, 2004). These findings send a strong message to developers of course management systems and other e-learning technologies that stability must be the top priority or else instructors may not experiment with a tool long enough to adopt it completely. We also learned that most instructors adopt Blackboard as individual features, and thus may not be using the tool for everything available in the CMS package and may be looking for other options, such as commercial grading programs, to supplement their use of the CMS. It 
is thus important for institutions to not only support instructors in experimenting with/using a CMS, but also other programs that may be necessary to supplement the CMS for particular teachers' needs. This may not be what university administrators and support staff want to hear, especially if they feel that by supporting a CMS they are answering all of the instructors' needs. In this study we found that a CMS is rarely a sufficient "all-in-one" package, and many instructors are looking for other resources.

We also learned that for some instructors, it seemed important to have a tool that allows for personal adaptation so that instructor methodology can better align with the CMS. Herrington, Reeves, and Oliver (2005) warn that we may be suffering from digital myopia as instructional technology designers, in that we have forgotten what our true purpose is in designing these tools. Instead of focusing on improving education, these authors contest that CMS technologies focus on delivering information. We found this to be true in our interviews, and when instructors attempted to use pedagogies that departed from information transmission, they often felt that the CMS was inflexible and unable to adapt to their preferred way of teaching.

$\underline{\text { In future studies, it would be interesting to research how critical the ability to adapt a }}$ CMS is for instructors. Rogers (2003) argues that re-invention of an innovation leads to a faster rate of adoption and a higher degree of sustainability (p. 183). Rogers posits that it is possible for $\underline{\text { flexibility to be designed into an innovation, like a CMS, to allow for better adaptability. }}$ Designing more flexibility into CMS tools may be critical because there are different instructional theories, whether implicitly or explicitly acknowledged, that are employed at a university, and the best method for matching a single tool to all of these instructional methodologies may be for instructors to be able to adapt the tool to fit their unique situations. 
Insofar as adaptation is able to occur (because the tool is flexible enough to allow it and because instructors are skilled enough to do so), the benefit derived from educational technologies, like course management systems, may increase.

Few educational technologies are as widely adopted and implemented as course management systems. With the recently announced merger of Blackboard and WebCT, the adoption and penetration of a single company (and in the future, most likely a single tool) will be extremely high. More studies are needed to better understand what situations this level of adoption may create for individual instructors, students, and institutions. By understanding the needs of instructors who are adopting CMS features, designers may be able to create more flexible, more easily adaptable, and ultimately more useful tools that will better serve the needs of all instructors. 


\section{References}

Ali, A. (2003). Faculty Adoption of Technology: Training Comes First. Educational Technology, 43(2), 51-53.

Arnone, M. (2002). Course-management outfits still seek elusive profits. The Chronicle of Higher Education. July 12, 2002.

Bennett, J., \& Bennett, L. (2003). A Review of Factors that Influence the Diffusion of Innovation When Structuring a Faculty Training Program. Internet and Higher Education, 6(1), 5363.

Dexter, R. R. (2005). Instructional Leadership for Systemic Change: The Story of San Diego's Reform. School Administrator, 62(9), 57-57.

Dutton, W. H. Cheong, P. H., \& Park, N. (2004). The social shaping of a virtual learning environment: The case of a university-wide course management system. Electronic Journal of e-Learning, 2(1), 69-80.

Ellsworth, J. B. (2000). Surviving change: A survey of educational change models. Syracuse, NY: ERIC Clearinghouse on Information and Technology.

Ellis, C. (2004). Benchmarking Blackboard: From champions to transformers. Retrieved March 29, 2006, from http://www.bbmatters.net/bbmattersproject/ Articles/article_item.asp?SubmitArticleID=50

Ely, D. P. (1990). Conditions That Facilitate the Implementation of Educational Technology Innovations. Journal of Research on Computing in Education, 23(2), 298-305.

Ely, D. P. (1999). Conditions that facilitate the implementation of educational technology innovations. Educational Technology, 39(6), 23-27. 
Farquhar, J. D., \& Surry, D. W. (1994). Adoptional Analysis: An Additional Tool for Instructional Developers. Educational and Training Technology International, 31(1), 1925 .

Fitzgibbon, K. M., \& Jones, N. (2004). Jumping the Hurdles: Challenges of Staff Development Delivered in a Blended Learning Environment. Journal of Educational Media, 29(1), 2535.

Fleming, J., \& Love, M. (2003). A Systemic Change Model for Leadership, Inclusion, and Mentoring (SLIM). Early Childhood Education Journal, 31(1), 53.

Glaser, Barney G. (1978). Theoretical sensitivity: advances in the methodology of grounded theory. Mill Valley, CA: Sociology Press.

Glaser. B. G. \& Strauss, A. L. (1967). The discovery of grounded theory: Strategies for qualitative research. Mill Valley, CA: Sociology Press.

Hall, G. \& Hord, S. (1987). Change in schools: Facilitating the process. Albany, NY: State University of New York Press.

Havelock, R. \& Zlotolow, S. (1995). The change agent's guide. Englewood Cliffs, NJ: Educational Technology Publications.

Herrington, J., Reeves, T. C., \& Oliver, R. (2005). Online learning as information delivery: Digital myopia. Journal of Interactive Learning Research, 16(4), 353-367.

Hutchins, H. M. (2001). Enhancing the business communication course through WebCT. Business Communications Quarterly, 64(3), 87-95.

Irani, T., \& Telg, R. (2001). Planning for the Next Wave: Assessing Current Faculty Distance Education Training and Development Needs. Journal of Applied Communications, 85(4), 7-18. 
Joseph, R., \& Reigeluth, C. M. (2005). Formative research on an early stage of the systemic change process in a small school district. British Journal of Educational Technology, $36(6), 937-956$.

Kagima, L. K., \& Hausafus, C. O. (2001). Faculty: The Central Element in Instructional Technology Integration. Journal of Family and Consumer Sciences: From Research to Practice, 93(4), 33-36.

Klecker, B. M. (2002). Evaluation of electronic Blackboard enhancement of a graduate course in school counseling. Paper presented at the conference for the Mid-South Educational Research Association, held at Chattanooga, TN.

Massimo, V. S. (2003). Integrating the WebCT discussion feature into social work courses: An assessment focused on pedagogy and practicality. Journal of Technology in Human Services. 22(1), 49-64.

McCarney, J. (2004). Effective Models of Staff Development in ICT. European Journal of Teacher Education, 27(1), 61-72.

Miller, D. N., George, M. P., \& Fogt, J. B. (2005). Establishing and sustaining research-based practices at Centennial School: A descriptive case study of systemic change. Psychology in the Schools, 42(5), 553-567.

Merriam, S. B. (1998). Qualitative research and case study applications in education. San Francisco: Jossey-Bass.

Moersch, C. (1995). Levels of Technology Implementation (LoTi): A Framework for Measuring Classroom Technology Use. Learning and Leading with Technology, 23(3), 40-42.

Moersch, C. (1996). Computer Efficiency: Measuring the Instructional Use of Technology. Learning and Leading with Technology, 24(4), 52-56. 
Morgan, G. (2003). Faculty use of course management systems. Denver: Educause Center for Applied Research.

Pollack, T. A. (2003). Using a course management system to improve instruction. Paper presented at the annual conference of the Association of Small Computer Users in Education, held at Myrtle Beach, South Carolina.

Rogers, E. M. (2003). Diffusion of innovations (5 ${ }^{\text {th }}$ ed.). New York: The Free Press.

Reigeluth, C. M. (1994). Introduction: The imperative for systemic change. In C. M. Reigeluth, \& R. J. Garfinkle (Ed.)'s Systemic change in education. Englewood Cliffs, NJ: Educational Technology Publications.

Reigeluth, C. \& Garfinkle, R. (1994). Systemic change in education. Englewood Cliffs, NJ: Educational Technology Publications.

Surry, D. W. \& Ensminger, D. C. (2002, April). Perceived importance of conditions that facilitate implementation. Paper presented at the annual meeting of the American Educational Research Association, New Orleans, LA.

Vessell, D. C. (2001). Comparing the WWW and WebCT to traditional methods of supporting an undergraduate psychology course: Is it effective? Unpublished doctoral dissertation. University of Missouri-Columbia.

Yaskin, D., Everhart, D. (2002). Blackboard Learning System (Release 6) Product Overview White Paper. Retrieved March 20, 2006, from http://products.blackboard.com/cp/release6/LSR6WP.pdf.

Yaskin, D., Gilfus, S. (2001). Blackboard 5: Introducing the Blackboard 5: Community Portal System. Retrieved March 20, 2006, from http://company.blackboard.com/docs/cp/orientation/CommunityPortalWhitePaper.pdf. 
Yaskin, D., Gilfus, S. (2002). Blackboard 5: Introducing the Blackboard 5: Learning System. Retrieved March 20, 2006, from http://company.blackboard.com/docs/cp/orientation/EnterpriseLearningWhitePaper.pdf.

Yip, M. C. W. (2004). Using WebCT to teach courses online. British Journal of Educational Technology, 35(4), 497-501.

Zaltman, G. \& Duncan, R. (1977). Strategies for planned change. New York: John Wiley and Sons. 
Appendix

Figures

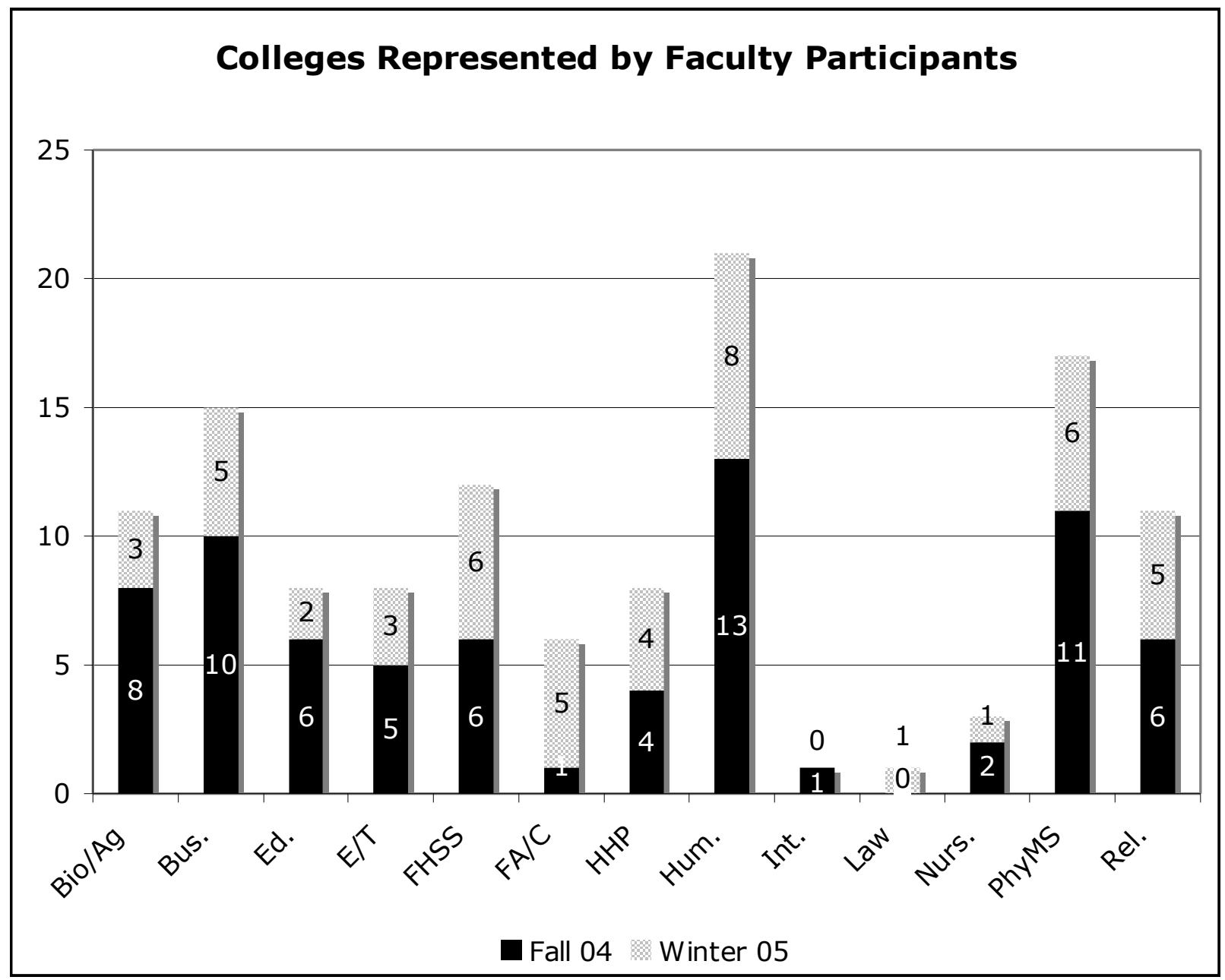

Figure 1. Description of the colleges represented by faculty who participated in the surveys.

These are colleges represented by the abbreviations: Biology and Agriculture; Business;

Education; Engineering and Technology; Family, Home, and Social Sciences; Fine Arts and Communications, Health and Human Performance, Humanities, International, Law, Nursing, Physical and Mathematical Sciences, and Religious Education. 


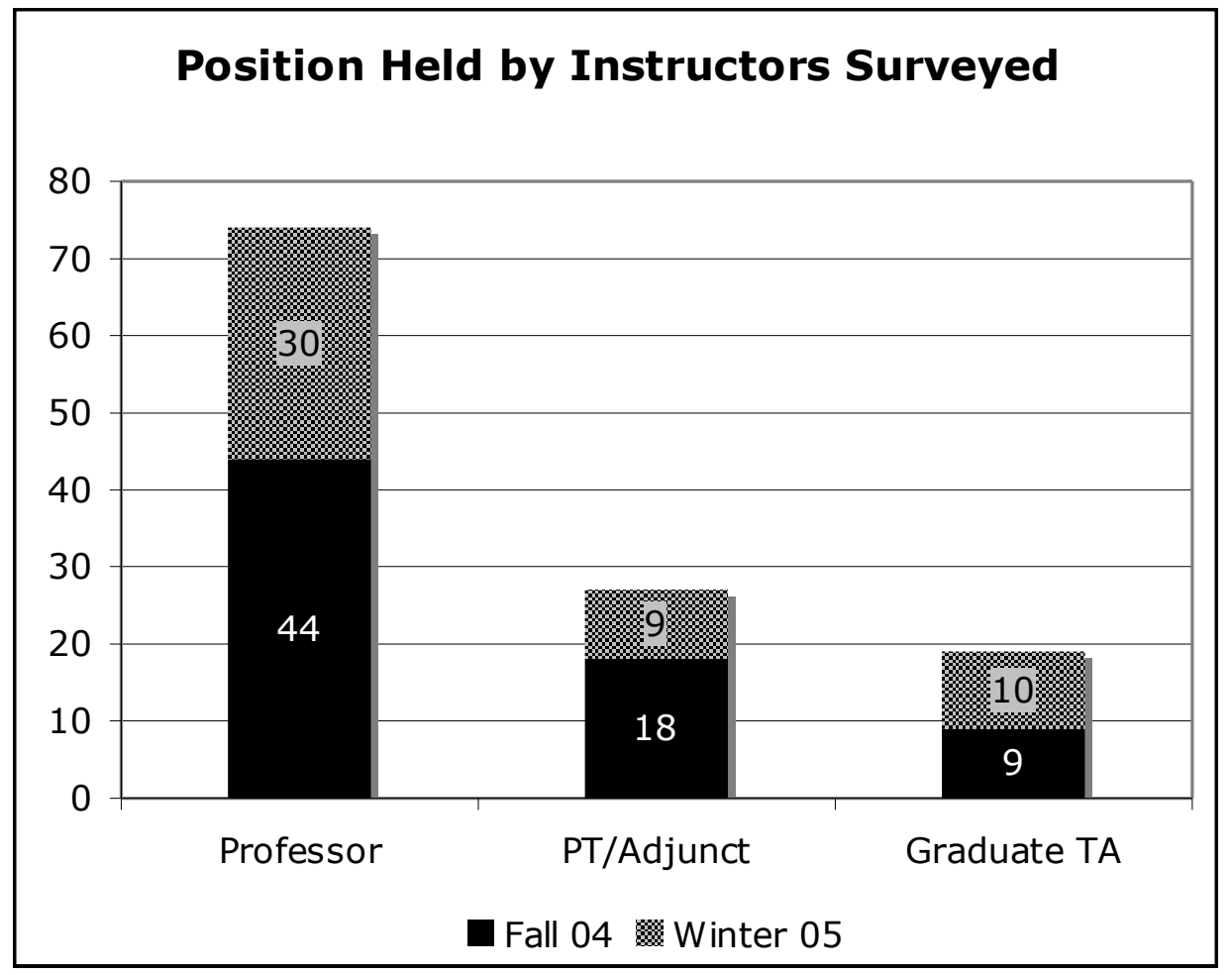

Figure 2. Description of the positions held by the participants in the surveys. 

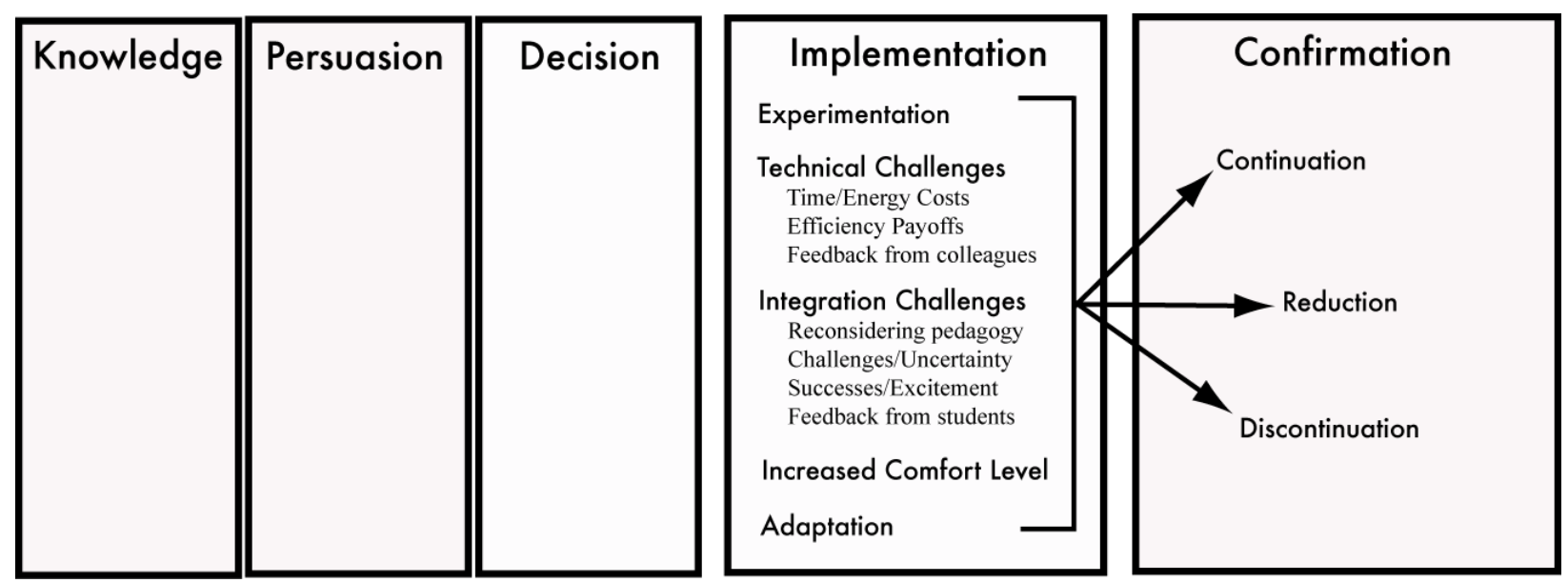

Figure 3. A depiction of the implementation and confirmation patterns found in this research study, and how they relate to Rogers' (2003) Innovation-Decision Model. The additions made by this study explain in more detail the kinds of experiences instructors have as they implement Blackboard features into their practices. 


\section{Tables}

Table 1.

Open-ended survey questions administered to a sample of faculty who use Blackboard.

\section{Survey Questions}

1. How has using Blackboard changed how you use in-class time?

2. If you have decreased in-class meeting times because of an online component, please explain what you have done and why. (If not, leave blank.)

3. Please describe any technical problems you have encountered.

4. What other concerns or problems do you have with using Blackboard in your classes?

5. Explain the best way that you've used Blackboard in a course.

6. Please share any additional comments you may have regarding Blackboard.

7. *What was the most important thing Blackboard has done for your classes? 
Table 2.

Description of the demographics of interview participants by college and gender.

\begin{tabular}{llll}
\hline & \multicolumn{3}{c}{ Gender } \\
\cline { 2 - 4 } College & Male & Female & Total \\
\hline Biology/Agriculture & 6 & 0 & 6 \\
Business & 3 & 0 & 3 \\
Education & 0 & 2 & 2 \\
Engineering/Technology & 3 & 0 & 4 \\
Fine Arts and Communications & 3 & 1 & 4 \\
Family, Home and Social Sciences & 2 & 0 & 2 \\
Health and Human Performance & 1 & 0 & 1 \\
Humanities & 5 & 0 & 5 \\
Nursing & 0 & 2 & 2 \\
Physical and Mathematical Sciences & 1 & 0 & 1 \\
Religion & 2 & 0 & 2 \\
Total & 26 & 5 & 31 \\
\hline
\end{tabular}


Table 3.

Interview protocol used in semi-structured interviews with faculty participants.

1. Can you tell me about your experience with Blackboard?

\section{Context (5 min)}

1. What is your course about?

2. About how many students do you have in each section?

3. Where is the course situated in their programs? (required, optional, mostly freshman, mostly seniors, etc?)

4. How long have you been teaching this course?

\section{Usage (10 min)}

1. Do you use Bb? Why do you use Bb (or why do you not?)

2. What persuaded you to use $\mathrm{Bb}$ (what would persuade you?)

3. What $\mathrm{Bb}$ features do you use? How often? Why do you choose to use them?

4. Can you show me your Bb site? Ask them for a tour.

5. If they do not mention a feature, prompt and ask them if they knew about it and had ever thought about using it and why they do not.

\section{Satisfaction (10 min)}

1. What do you think about Blackboard? Has it worked well? Why or why not?

2. What are the benefits from using $\mathrm{Bb}$ ?

3. What have been the challenges from using $\mathrm{Bb}$ ?

4. What do you NEED a CMS to be able to do?

5. What would you LIKE it to be able to do if it could be possible?

\section{Efficiency (10 min)}

1. Does Bb help you be more efficient? How?

2. Which features save you the most time?

\section{Learning (20 min)}

1. Do you feel that using Bb helps you teach more effectively? In what ways? How do you use it?

2. Do you feel that using Bb helps students learn more effectively? In what ways?

3. How do you think a tool like $\mathrm{Bb}$ could be used to improve learning in your subject area?

4. If you use the discussion/chat tools, how do you use them? What has worked well? What hasn't worked well? 
CMS Experiences 46 